\title{
USIA DAN BUDAYA PANTANGMAKANAN MEMPENGARUHI PENYEMBUHAN LUKA PERINEUM PADA IBU NIFAS HARI KE 7
}

\author{
SondangSidabutar, \\ (Akbid Griya Husada Surabaya, sondang_sidabutar73@yahoo.co.id
}

\begin{abstract}
ABSTRACK
Wound healing is a long time in there covery process because of damage to the skin or skin tissue disintegritas. According to Rustam Mochtar(1998), the injured in the birth canal when not accompanied by infection will heal within6-7days. Based on the results of a survey on BPS Ny. Arifin S. Surabaya, from as many as 7 of 10 respondents (70\%) found the wound is still wet. The purpose of this study was to determine age and cultural picture of incontinence on postpartum mother's perineal wound healing on the seventh day in the BPS Ny. Arifin S. Surabaya.

In this research using descriptive method with the study population was all mothers with post natal on the seventh day stit chesin the perineum which controls BPS Ny. Arifin S. Surabaya period from July to August 2008 as many as 49 people. Sampling of non-probability sampling with a sampling technique is saturated. By using questionnaires and observation sheets as research instruments. Data created frequency tables and cross tabulations and then summed.

Based on the results of research on maternal postnatal day 9 to 7, obtained the majority of postnatal mother saged <35 years of the perineal wound healed as many as 24 people (66.66\%) and in postpartum mothers who do not abstain from the majority of the perineal wound healed as many as 17 people (77.27\%).

By looking at these result it can be concluded that the perineal wound healing can be influenced byculture age and abstinence from food. Therefore, the provision of good information and right by the health officer of the perineal wound care will affect the success of the perineal wound healing process.
\end{abstract}

\begin{abstract}
ABSTRAK
Penyembuhan luka adalah panjang waktu proses pemulihan pada kulit karena adanya kerusakan atau disintegritas jaringan kulit. Menurut Rustam Mochtar (1998), luka- luka pada jalan lahir bila tidak disertai infeksi akan sembuh dalam $6-7$ hari. Berdasarkan hasil survei pendahulan di BPS Ny. Arifin S. Surabaya, dari 10 responden sebanyak 7 orang (70\%) ditemukan luka masih basah. Tujuan dari penelitian ini adalah mengetahui gambaran usia dan budaya tarak terhadap penyembuhan luka perineum ibu nifas hari ke 7 di BPS Ny. Arifin S. Surabaya.

Dalam penelitian ini menggunakan metode deskriptif dengan populasi penelitian adalah seluruh ibu nifas hari ke 7 dengan luka jahitan perineum yang kontrol di BPS Ny. Arifin S. Surabaya periode Juli - Agustus 2008 sebanyak 49 orang. Pengambilan sampel secara non probability sampling dengan teknik sampling jenuh. Dengan menggunakan kuesioner dan lembar observasi sebagai instrumen penelitian. Data dibuat tabel frekuensi dan tabulasi silang kemudian disimpulkan.

Berdasarkan hasil penelitian pada 49 orang ibu nifas hari ke 7 , didapatkan mayoritas ibu nifas berusia < 35 tahun luka perineum sembuh yaitu sebanyak 24 orang $(66,66 \%)$ dan pada ibu nifas yang melakukan pantang mayoritas luka perineum tidak sembuh yaitu sebanyak 17 orang $(77,27 \%)$.
\end{abstract}


Dengan melihat hasil tersebut maka dapat diambil kesimpulan bahwa penyembuhan luka perineum dapat dipengaruhi oleh usia dan budaya pantang makanan. Oleh karena itu, pemberian informasi yamg baik dan benar oleh petugas kesehatan tentang perawatan luka perineum akan mempengaruhi keberhasilan proses penyembuhan luka perineum.

\section{Kata Kunci: Usia, Budaya, Penyembuhan Luka}

\section{PENDAHULUAN}

Hakikat pembangunan nasional adalah menciptakan manusia Indonesia seutuhnya, serta pembangunan seluruh masyarakat Indonesia menuju masyarakat adil dan makmur, berdasarkan Pancasila dan Undang-Undang Dasar 1945. Oleh karena itu, pembangunan di bidang kesehatan harus dilaksanakan sebagai bagian integral dari pembangunan nasional. Karena pada dasarnya pembangunan nasional di bidang kesehatan, berkaitan erat dengan peningkatan mutu sumber daya manusia, yang merupakan modal dasar dalam melaksanakan pembangunan. (Siti Saleha, 2007:1).

Salah satu indikator untuk menentukan derajat kesehatan suatu bangsa, ditandai dengan tinggi rendahnya angka kematian ibu dan bayi. Hal ini merupakan suatu fenomena yang mempunyai pengaruh besar terhadap keberhasilan pembangunan kesehatan. (Sitti Saleha, 2007:1)

Masa nifas (puerperium) adalah masa setelah placenta lahir, dan berakhir ketika alat-alat kandungan kembali, seperti keadaan sebelum hamil. Masa nifas berlangsung selama kira-kira 6 minggu. (Helen Varney, 2007).

Masa nifas merupakan hal penting untuk diperhatikan, guna menurunkan angka kematian ibu dan bayi di Indonesia. Dari berbagai pengalaman dalam menanggulangi kematian ibu dan bayi di banyak negara, para pakar kesehatan menganjurkan upaya pertolongan difokuskan pada periode intra partum. Upaya ini telah terbukti menyelamatkan lebih dari separuh ibu bersalin dan bayi baru lahir yang disertai dengan penyulit proses persalinan atau komplikasi yang mengancam keselamatan jiwa. (Sitti Saleha, 2007)

Menurut data WHO, sebanyak 99

persen kematian ibu akibat masalah persalinan atau kelahiran, terjadi di negaranegara berkembang. Data resmi yang dimiliki Departemen Kesehatan menyebutkan, Angka Kematian Ibu (AKI) di Indonesia terus mengalami penurunan. Meski secara besaran angka kematian (AKI) di Indonesia masih tinggi. (www.suarapembaruan.com)

Angka kematian ibu melahirkan, di Indonesia masih tertinggi di negara ASEAN yakni 248/100.000 kelahiran menurut Badan Pusat Statistik (BPS) tahun 2006. Angka ini masih jauh dari target tujuan pembangunan millenium (Millenium Development Goals/MDGs) yakni 125/100.000 kelahiran pada tahun 2015. (www.suarapembaruaan.com)

Menurut Survei Demografi dan Kesehatan Indonesia (SDKI) tahun 2007 kematian ibu menjadi 228/100.000 kelahiran hidup.(DepKes RI. 2007)

Angka kematian ibu bersalin di Jawa Timur tahun 2000 sebesar 356 dengan penyebab kematian terbesar adalah perdarahan $(36,23 \%), \quad$ preeklamasi $(23,88 \%)$, infeksi nifas $(6,56 \%)$, dan lainlain $(34,83 \%)$.

(www.google.com/library@lib.unair.ac.id)

Angka kematian ibu disebabkan beberapa hal antara lain : atonia uteri 50\%$60 \%$, retensio plasenta $16 \%-17 \%$, sisa placenta 23\%-24\%, laserasi jalan lahir 4\%$5 \%$, kelainan darah 0,5\%-0,8\%. (Rustam Mochtar, 1998) 
Sesudah partus terdapat luka-luka di beberapa tempat pada jalan lahir. Pada hari-hari pertama post partum harus dijaga agar luka-luka ini tidak dimasuki kumankuman dari luar. Oleh sebab itu, semua alat dan kain yang berhubungan dengan genital harus suci hama. (Hanifa Winkjosastro, 2005)

Luka-luka pada jalan lahir yaitu luka episiotomi dan luka ruptur, diharapkan dapat segera sembuh, agar komplikasi pada masa nifas terutama infeksi pada jalan lahir tidak terjadi. (http://creasoft.wordpress.com)

Menurut Rustam Mochtar (1998), luka-luka pada jalan lahir bila tidak disertai infeksi akan sembuh dalam 6-7 hari.

Infeksi nifas merupakan keadaan abnormal pada masa nifas, yang disebabkan oleh masuknya kuman-kuman ke dalam alat genetalia pada waktu persalinan dalam nifas. (Sitti Saleha, 2007)

Infeksi akut ditandai dengan demam, sakit di daerah infeksi, berwarna kemerahan, fungsi organ terganggu. Gambaran klinis infeksi nifas dapat berbentuk infeksi lokal dan infeksi umum. Infeksi lokal yaitu pembengkakan luka episiotomi, terjadi pernanahan, perubahan warna kulit, pengeluaran lochea bercampur nanah, mobilitasi terbatas karena rasa nyeri, temperatur badan meningkat. Infeksi umum yaitu tampak sakit dan lemah, temperatur meningkat dan rasa sesak. Kesadaran gelisah sampai menurun dan koma, terjadi gangguan involusi uterus, lochea berbau dan bernanah serta kotor. (Eny Retna Ambarwati dan Diah Wulandari, 2007)

Berdasarkan data di BPS Ny. Arifin S Surabaya, ibu yang mengalami luka jahitan saat persalinan semakin meningkat. Pada tahun 2005 yang mengalami luka jahitan saat persalinan sebanyak 318 orang dari 530 persalinan dengan persentase $60 \%$. Tahun 2006 ibu yang mengalami luka jahitan saat persalinan sebanyak 364 orang dari 536 persalinan dengan persentase
67,91\%. Tahun 2007 ibu yang mengalami luka jahitan saat persalinan sebanyak 395 orang dari 542 persalinan, dengan persentase $72,87 \%$.

Data tersebut di atas dapat dilihat pada tabel di bawah ini :

Tabel 1.1 Data ibu bersalin yang mengalami luka jahitan tahun 2005-2007 di BPS Ny. Arifin S. Surabaya

\begin{tabular}{|c|c|c|c|c|c|}
\hline \multirow{2}{*}{$\begin{array}{c}\text { Tahu } \\
\text { n }\end{array}$} & \multirow{2}{*}{$\begin{array}{c}\text { Jumlah } \\
\text { IbuBersal }\end{array}$} & \multicolumn{3}{|c|}{ Luka Perineum } \\
\cline { 3 - 6 } & in & \multicolumn{2}{|c|}{ Ya } & \multicolumn{2}{c|}{ Tidak } \\
\cline { 3 - 6 } & 530 & 31 & 60 & 21 & $\%$ \\
\hline 2005 & 536 & 8 & 67,9 & 2 & 32,0 \\
2006 & 536 & 36 & 1 & 17 & 9 \\
2007 & 542 & 4 & 72,8 & 2 & 27,1 \\
& & 39 & 7 & 14 & 3 \\
& & 5 & & 7 & \\
\hline
\end{tabular}

Sumber buku register BPS Ny. Arifin S. Surabaya tahun 2005 - 2007

Hasil penelitian pendahuluan bulan Juli 2008 dari 10 responden Ibu nifas hari ke 7 dengan luka jahitan perineum ditemukan luka jahitan basah dan belum menutup sebanyak 7 orang (70\%), sedangkan 3 orang lainnya (30\%) didapatkan luka jahitan perineum sudah menutup dan kering. Dari 7 orang yang luka jahitan perineumnya basah, 5 orang $(71,4 \%)$ melakukan tarak, sedangkan 2 orang $(28,5 \%)$ tidak melakukan tarak. Berdasarkan persentase dapat disimpulkan banyak ibu nifas dengan luka perineum yang belum sembuh karena kebiasaan tarak.

Dari 10 responden Ibu Nifas hari ke 7 dengan luka jahitan perineum, 3 orang $(42,8 \%)$ yang luka jahitan kering atau sembuh berusia < 35 tahun. Dari 7 orang yang luka jahitan basah ditemukan 5 orang berusia $<35$ tahun dan 2 orang $(28,5 \%)$ berusia $\geq 35$ tahun. Berdasarkan penelitian pandahuluan yang dilakukan dapat disimpulkan bahwa ibu nifas hari ke 7 sebanyak $70 \%$ mempunyai luka jahitan perineum masih basah dan belum menutup. Dari 7 orang yang luka jahitan perineum 
basah 5 orang $(71,4 \%)$ melakukan tarak dan yang berusia $\geq 35$ tahun sebanyak 2 orang $(28,5 \%)$.

Beberapa faktor predisposisi terjadinya infeksi masa nifas yaitu kurang gizi atau malnutrisi, anemia, higiene, kelelahan, proses persalinan bermasalah seperti: partus lama/macet, korioamnionitis, persalinan traumatik, kurang baiknya proses pencegahan infeksi, manipulasi yang berlebihan. (Abdul Bari Syaifudin, 2002)

Faktor-faktor yang dapat juga berpengaruh pada penyembuhan luka yaitu karakteristik ibu (umur, pendidikan, paritas), faktor penyakit, budaya, nutrisi,personal hygiene, dan lingkungan. (http://creasoft.wordpress.com)

Usia reproduksi yang untuk kehamilan dan persalinan adalah $20-30$ tahun, kematian maternal pada wanita hamil dan melahirkan pada usia di bawah 20 tahun ternyata $2-5$ kali lebih tinggi daripada kematian maternal yang terjadi pada usia 20 - 29 tahun. Kematian maternal meningkat kembali sesudah usia 30 - 35 tahun. (Hanifa Winkjosastro, 2005)

Penyembuhan luka lebih cepat terjadi pada usia muda daripada orang tua. Orang yang sudah lanjut usianya tidak dapat mentolerir stress seperti trauma jaringan atau infeksi. (www.referensikesehatan.com)

Budaya tarak telur, ikan, dan daging ayam juga akan mempengaruhi penyembuhan luka, karena asupan gizi yang diperlukan ibu berkurang. (http://www.owner.theavelle.net)

Luka pada perineum akibat episiotomi, ruptura, atau laserasi merupakan daerah yang tidak mudah untuk dijaga agar tetap bersih dan kering. Pengamatan dan perawatan khusus diperlukan untuk menjamin agar daerah tersebut sembuh dengan cepat dan mudah. (Helen Farrer, 2001).

Kondisi perineum yang terkena lokia dan lembab akan sangat menunjang perkembangbiakan bakteri yang dapat menyebabkan timbulnya infeksi pada perineum. Munculnya infeksi pada perineum dapat merambat pada saluran kandung kemih ataupun pada jalan lahir yang dapat berakibat pada munculnya komplikasi infeksi kandung kemih maupun infeksi pada jalan lahir. Penanganan komplikasi yang lambat dapat menyebabkan terjadinya kematian pada ibu post pastum mengingat kondisi fisik ibu post partum masih lemah (Suwiyoga, 2004). (http://owner.theavella.net)

Perawatan perineum, nutrisi, personal hygiene yang dilakukan dengan baik dapat menghindarkan terjadinya infeksi, komplikasi, dan kematian ibu post partum. (http://owner.theavella.net)

Dari uraian di atas yaitu meningkatnya jumlah ibu yang mengalami luka jahitan saat persalinan dan beberapa faktor yang menyebabkan terjadinya infeksi masa nifas, maka perlu dilakukan penelitian tentang gambaran antara usia dan budaya pantang makanan terhadap penyembuhan luka perineum ibu nifas hari ke 7 .

\section{METODE PENELITIAN}

Penelitian ini menggunakan desain deskriptif. Pada desain ini hanya menggambarkan saja sejelas mungkin tanpa mencoba menganalisis bagaimana dan mengapa fenomena tersebut terjadi. (Didik Budijanto. 2005)

Sampel diambil dengan cara deskriptif (Non Probability) sampling dengan teknik sampling jenuh yaitu cara dimana seluruh anggota populasi menjadi sampel.

Dalam penelitian ini, peneliti melakukan pengumpulan data primer berdasarkan kuesioner tentang budaya yang telah diberikan kepada responden yang memenuhi kriteria dan hasil observasi penyembuhan luka perineum dari peneliti. 
Data dibuat tabel frekuensi kemudian dibuat tabulasi silang lalu dianalisis.

HASIL PENELITIAN

Tabel 1 Distribusi frekuensi tingkat pendidikan ibu nifas hari ke7

\begin{tabular}{ccc}
\hline $\begin{array}{c}\text { JenisPendi } \\
\text { dikan }\end{array}$ & $\begin{array}{c}\text { Freku } \\
\text { ensi }\end{array}$ & $\begin{array}{c}\text { Persen } \\
\text { tase } \\
(\%)\end{array}$ \\
\hline SD & 11 & 22,45 \\
SMP & 14 & 28,57 \\
SMA & 15 & 30,61 \\
Perguruan & 9 & 18,37 \\
Tinggi (PT) & & \\
\hline Jumlah & 49 & 100 \\
\hline
\end{tabular}

Sumber : Data primer hasil kuesioner yang sudah diteliti

Berdasarkan tabel 1 mayoritas ibu nifas berpendidikan SMA yaitu sebanyak 15 orang $(30,61 \%)$.

Tabel 2 Distribusi frekuensi paritas ibu nifas hari ke 7

\begin{tabular}{ccc}
\hline Paritas & $\begin{array}{c}\text { Frekue } \\
\text { nsi }\end{array}$ & $\begin{array}{c}\text { Persent } \\
\text { ase (\%) }\end{array}$ \\
\hline $\begin{array}{c}\text { Primigravi } \\
\text { da } \\
\text { Multrigra } \\
\text { vida }\end{array}$ & 21 & 42,86 \\
\hline Jumlah & 28 & 57,14 \\
\hline
\end{tabular}

Sumber : Data primer hasil kuesioner yang sudah diteliti

Berdasarkan tabel 2 mayoritas ibu nifas adalah multigravida yaitu sebanyak 28 orang $(57,14 \%)$.

Tabel .3 Distribusi frekuensi usia ibu nifas hari ke -7

\begin{tabular}{ccc}
\hline Usia & Frekuensi & $\begin{array}{c}\text { Persentase } \\
(\boldsymbol{\%})\end{array}$ \\
\hline$<35$ tahun & 36 & 73,46
\end{tabular}

\begin{tabular}{ccc}
$\geq 35$ tahun & 13 & 26,54 \\
\hline Jumlah & 49 & 100
\end{tabular}

Sumber : Data primer hasil kuesioner yang sudah diteliti

Berdasarkan tabel 3 ibu nifas hari ke 7 yang kontrol mayoritas berusia < 35 tahun yaitu sebanyak 36 orang $(73,46 \%)$.

Tabel.4 Distribusi frekuensi budaya pantang makanan ibu nifas hari ke 7

\begin{tabular}{ccc}
\hline $\begin{array}{c}\text { Budaya } \\
\text { Pantang } \\
\text { Makanan }\end{array}$ & Frekuensi & $\begin{array}{c}\text { Persentase } \\
(\%)\end{array}$ \\
\hline Pantang & 22 & 44,90 \\
TidakPantang & 27 & 55,10 \\
\hline Jumlah & 49 & 100 \\
\hline
\end{tabular}

Sumber : Data primer hasil kuesioner yang sudah diteliti

Berdasarkan tabe .4 mayoritas ibu nifas tidak melakukan pantang yaitu sebanyak 27 orang $(55,10 \%)$.

Tabel 5 Distribusi frekuensi penyembuhan luka perineum

\begin{tabular}{ccc}
\hline $\begin{array}{c}\text { Luka } \\
\text { Perineum }\end{array}$ & Frekuensi & $\begin{array}{c}\text { Persentase } \\
(\%)\end{array}$ \\
\hline Luka sembuh & 29 & 59,18 \\
Luka & 20 & 40,82 \\
tidaksembuh & \multicolumn{3}{c}{100} \\
\hline Jumlah & 49 & \multicolumn{2}{c}{100} \\
\hline $\begin{array}{l}\text { Sumber } \\
\text { kuesioner yang sudah diteliti }\end{array}$ & Data primer & hasil
\end{tabular}

Berdasarkan tabel 5 mayoritas ibu nifas keadaan luka perineum sembuh yaitu sebanyak 29 orang $(59,18 \%)$. 


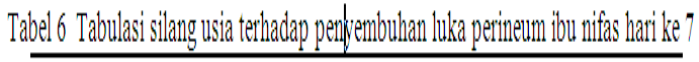

\begin{tabular}{|c|c|c|c|c|c|}
\hline \multirow{3}{*}{ Usia } & \multicolumn{3}{|c|}{ Luka perineum } & \multirow{3}{*}{ Jumlah } & \multirow{3}{*}{$\%$} \\
\hline & \multicolumn{2}{|c|}{ Sembuln } & Tiddaksembuh & & \\
\hline & $\Sigma$ & $\%$ & $\sum \%$ & & \\
\hline$<35$ tahum & 24 & 66,66 & $12 \quad 33,34$ & 36 & 100 \\
\hline$\geq 35$ tahum & $j$ & 38,46 & $8 \quad 61,54$ & 13 & 100 \\
\hline Jumlah & 29 & 59,18 & $20 \quad 40,82$ & 49 & 100 \\
\hline
\end{tabular}

Berdasarkan gambaran antara variabel usia terhadap penyembuhan luka, didapatkanmayoritas luka perineum sembuh pada usia $<35$

tahun sebanyak 24 orang $(66,66 \%)$

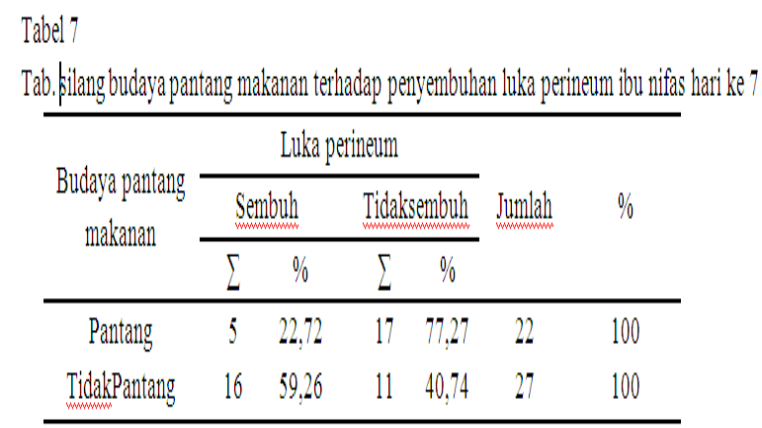

Berdasarkan gambaran antara variabel budaya pantang makanan terhadap penyembuhan luka, didapatkan mayoritas luka perineum tidak sembuh pada ibu yang melakukan budaya pantang.

\section{A. PEMBAHASAN}

Dilihat dari tabel 1 tentang umur ibu bersalin didapatkan mayoritas umur 20-35 tahun sebanyak 42 orang $(51,85 \%)$.

Menurut Winkjosastro (2002), usia reproduksi yang aman untuk kehamilan dan persalinan adalah 20-30 tahun sebab kehamilan di usia $<20$ tahun dan $>35$ tahun sering terjadi penyulit (komplikasi) baik pada ibu maupun janin. dibandingkan liuka perineum tidak sembuh pada usia $\geq 35$ tahun yaitu sebanyak 8 orang $(61,54 \%)$. makanan yaitu sebanyak 17 orang $(77,27 \%)$ dibandingkan luka perineum sembuh pada ibu yang tidak melakukan budaya pantang makanan yaitu sebanyak 16 orang $(59,26 \%)$.

Berdasarkan tabel 4 dapat disimpulkan bahwa mayoritas ibu umur $>35$ tahun melahirkan BBLR sebanyak $63,16 \%$ dibandingkan dengan ibu umur 20-35 tahun melahirkan BBLR sebanyak $53,76 \%$.

Guna menentukan adanya hubungan antara umur dengan keteraturan ANC dilakukan uji ChiSquare, didapatkan $\quad \chi_{\text {Hitung }}^{2}>\chi^{2}$ Tabel sehingga dapat disimpulkan ada hubungan antara umur dengan kejadian 
BBLR. Hal ini sesuai dengan teori bahwa umur kehamilan yang relativemuda $(<20$ tahun) dapatmenyebabkanpenyulit (komplikasi)

dalamkehamilanbaikpadaibumaupunjanin dikarenakanbelummatangnyaalatreprodu ksisehinggadapatmengakibatkankelahiran prematur, BBLR dancacatbawaan. Sedangkanpadausia> 35 tahun, ototototdasarpanggultidakelasticlagisehingga mudahterjadikomplikasibaiksaathamilma upunpersalinansepertipre-eklampsi,

hipertensi, diabetes mellitus, anemia yang juga dapat mengakibatkan kelahiran prematur atau BBLR

Dilihat dari tabel 2 tentang paritas ibu bersalin didapatkan bahwa mayoritas paritas ibu bersalin adalah multipara sebesar $40,74 \%$.

Menurut Abdul Bari Saifuddin (2002) jumlah anak yang banyak memerlukan persiapan baik secara mental maupun material. Kehamilan yang termasuk kategori "4 terlalu" diantaranya adalah terlalu sering hamil dan terlalu banyak anak. Hal ini selain akan mempengaruhi status kesehatan ibu dan anak juga mempengaruhi kesejahteraan keluarga.

Berdasarkan tabel 5 dapat disimpulkan bahwa bahwamayoritasibu multipara melahirkan BBLR sebanyak $75,76 \%$ dibandingkan dengan ibu primipara melahirkan BBLN sebanyak $77,42 \%$.

Untuk menentukan adanya hubungan antara paritas dengan kejadian BBLR dilakukan uji Chi-Square didapatkan $\chi_{\text {Hitung }}^{2}>\chi^{2}$ Tabel, sehingga dapat disimpulkan ada hubungan antara paritas ibu bersalin dengan kejadian BBLR. Hal ini sesuai dengan teori bahwa jarakkelahirandanbanyaknyaanakakansan gatberpengaruhterhadapkesehatanibudana naknya. Resiko BBLR dan kematian ibu ataupun anak akan meningkat apabila jarak kelahiran terlalu dekat. Hal ini dikarenakan fisik ibu dan rahim masih kurang cukup istirahat. Ibu yang sering hamil, lebih-lebih dengan jarak yang pendek akan menyebabkan ibu terlalu payah akibat dari hamil, melahirkan, menyusui, merawat anaknya terus menerus.

Dari hasil penelitian yang telah dilakukan dapat disimpulkan bahwa terdapat hubungan antara umur dan paritas ibu bersalin dengan kejadian BBLR. Sehingga dapat dicari solusi guna mencegah terjadinya berat badan lahir rendah yaitu dengan salah satu cara petugas kesehatan memberi pengetahuan atau penyuluhan tentang pentingnya pemeriksaan kehamilan sehingga ibu hamil mau memeriksakan kehamilannya secara teratur ke petugas kesehatan. Dengan pemeriksaan kehamilan secara teratur dapat mencegah terjadinya komplikasi atau timbulnya penyulit bagi ibu maupun janin antara lain anemia, abortus, partus prematurus, inersia uteri, BBLR, perdarahan pasca persalinan.

\section{SIMPULAN}

Dari hasil penelitian mengenai hubungan antara umur dan paritas ibu bersalin dengan kejadian Berat Badan Lahir Rendah di BPS Arifin Wonorejo Surabaya Tahun 2008, maka disimpulkan bahwa:

1. Ibu bersalin di BPS Ny. ArifinWonorejo Surabaya tahun 2008 mayoritasberumur 20-35 (51,85\%).

2. Ibu bersalin di BPS Ny. Arifin Wonorejo Surabaya tahun 2008 mayoritas multipara $(40,74 \%)$.

3. Ibu bersalin di BPS Ny. Arifin Wonorejo Surabaya tahun 2008 mayoritas melahirkan bayi dengan berat badan lahir rendah $(53,09 \%)$.

4. Ada hubungan antara umur dan paritas ibu bersalin dengan kejadian 
BBLR di BPS Ny. Arifin Wonorejo Surabaya.

\section{SARAN}

Penelitianinijauhdarisempurnadanp erluadanyapenelitianlanjutan yang lebihbermututentangfaktor-faktor lain yang dapatmempengaruhikejadian BBLR sertadapatmencakupwilayah yang lebihluasdanlebihbanyak.Diharapkan penelitian ini dapat meningkatkan pengetahuan dalam melakukan penelitian selanjutnya.

\section{DAFTAR PUSTAKA}

Anonimous. 2008. Jenjang Pendidikan. (online). id.wikipedia.org/wiki/ pendidikan, 24 Januari 2009.

Anonimous. 2006. Profil Kesehatan Jawa Timur. (online). www.Dinkes.go.id, 15 Januari 2009.

Bobak. 2004. Keperawatan Maternitas. Jakarta : EGC

Budijanto, Didik dan Prajoga. 2005. Metodologi Penelitian

DepKes RI. 2002. Pedoman Teknis Audit Maternal Perinatal di Tingkat Kabupaten Kota. Jakarta.

DepKes RI. 2004. Pedoman Pemantauan Wilayah Setempat Kesehatan Ibu dan Anak (PWS-KIA). Jakarta.

Dinkes Surabaya. 2004. Laporan PWS-KIA Tahun 2004. Surabaya.

Dinkes Surabaya 2005. Laporan PWS-KIA Tahun 2005. Surabaya.

Dinkes Surabaya 2006. Laporan PWS-KIA Tahun 2006. Surabaya.

Dinkes Surabaya 2007. Laporan PWS-KIA Tahun 2007. Surabaya.

Hellen, Farrer. 2001. Pengaruh Alkohol Terhadap Ibu Hamil. (online). (www.ayahbunda.com, 10 Januari 2009)

Klaus dan Fanaroff. 1998. Faktor-faktor Pengaruh Terjadinya BBLR. (online). (www.Dinkes.go.id, 18 Januari 2009)

Lucianawati, Mercy. 2008. Gender dan Kekerasan Terhadap Perempuan. (online). (www.ayahbunda.com, 15 Januari 2009).

Linda V, Wlsh. 2008. Pengaruh Plasenta Terhadap Pertumbuhan Janin. (online). (www.google.com, 15 Januari 2009)

Manuaba, IBG. 1998. Ilmu Kebidanan, Penyakit Kandungan, dan Keluarga Berencana Untuk Pendidikan Bidan. Jakarta : EGC

Mochtar, Rustam. 1998. Sinopsis Obstetri Jilid I. Jakarta : EGC.

Notoatmodjo, Soekidjo.2002.Metodologi Penelitian Kesehatan. Jakarta : Rineka Cipta

Notoatmodjo, Soekidjo. 2003.Pendidikan dan Prilaku Kesehatan.Yogyakarta: Andi Offset.

Notoatmodjo, Soekidjo. 2005. Metodologi Penelitian Kesehatan. Jakarta : Rineka Cipta.

Nursalam dan Pariani. 2001. Pendekatan Praktis Metodologi Riset Keperawatan. Jakarta : Sagung Seto.

Saifuddin, Abdul Bari. 2002. BukuAcuanNasionalPelayananKeseh atan Maternal dan Neonatal. Jakarta :Yayasan Bina PustakaSarwonoPrawirohardjo.

Saifuddin, Abdul Bari. 2002. BukuPanduanPraktisPelayananKeseh atan Maternal dan Neonatal. Jakarta :Yayasan Bina PustakaSarwonoPrawirohardjo.

Surasmi, Asrining. 2003. Perawatan Bayi Resiko Tinggi. Jakarta : EGC

Tjandar, Yofa. 2006. Penyebab Perkembangan Fisik pada Anak. (online). (www.google.com, 20 Januari 2009). 
